\title{
2009 GSA Geologic Time Scale
}

\author{
J.D. Walker, Department of Geology, 1475 Jayhawk \\ Boulevard, University of Kansas, Lawrence, Kansas 66045, \\ USA
}

J.W. Geissman*, Department of Earth and Planetary Sciences, MSC 03 2040, Northrop Hall, 1 University of New Mexico, Albuquerque, New Mexico 87131-0001, USA

Last year marked the 25th anniversary of the first Geological Society of America Geologic Time Scale (Palmer, 1983). The effort to prepare the first Society time scale was concurrent with the preparation of the 27 volumes of The Geology of North America to celebrate the Decade of North American Geology (DNAG). In 1982, an ad hoc time scale advisory committee was formed by the DNAG steering committee to encourage "uniformity among DNAG authors in the citation of numerical ages for chronostratigraphic units of the geologic time scale" (Palmer, 1983). The Time Scale Advisory Committee consisted of Z.E. Peterman (chairman), J.E. Harrison, R.L. Armstrong, and W.A. Berggren. Allison (Pete) Palmer, as centennial science program coordinator for GSA, was given the charge of compiling the committee's efforts.

The goal of the then-unique layout of the GSA-DNAG Geologic Time Scale, with each Phanerozoic era given identical column length, along with the Precambrian, was to provide a compact, succinctly organized yet suitably detailed (e.g., including uncertainties in ages of chronostratigraphic boundaries) compilation of our current knowledge of geologic time. In a recent communication to the second author, Pete wrote,

I do remember that I hand-drafted it at 2 or 3 times publication scale and pasted up the words. I also had to figure out how to format it so that it would all fit on one sheet (thus changing the scale for the numerical ages as things got older). I think the small plastic cards came later. I also think I consulted with various geochronologists to see which of several published numerical time scales was considered the most reliable, so none of the compilation was original-I just cribbed existing information. Fortunately, the stage-level nomenclature was a bit less messy than it is now...

Just think of how much has changed in 25 years (!), as recent and future modifications to the GSA Geologic Time Scale have and will continue to be done in a moment, in front of a computer.
Work on the current time scale started in 2007, and revision efforts focused on three aspects. The first was to update names and boundaries to capture changes documented in Gradstein et al. (2004) and to reflect more recent results of the many working groups of the International Commission on Stratigraphy. Other relevant work was also incorporated as needed (e.g., new publications on the Triassic time scale). Second, we updated the boundary ages using whatever sources were available. Last, the magnetic polarity time scale was extensively modified, especially for the early Mesozoic, in particular from the earliest Jurassic to the Permian-Triassic boundary. Some aspects of the GSA Geologic Time Scale do not conform to the recommendations of the International Commission on Stratigraphy. The names "Tertiary" and "Precambrian" were not dropped on the new time scale. The Quaternary, the status and boundaries of which are still being debated, was modified to reflect some of the pending recommendations. These differences were retained to best reflect the needs of GSA members and Divisions.

The compilers plan to keep the GSA Geologic Time Scale more up-to-date by having yearly reviews of important changes adopted by the International Commission on Stratigraphy, new publications, and information made available through other efforts, such as the Earth-Time Initiative. Loren Babcock (Ohio State University) will join us as a Geologic Time Scale compiler for the next revision. In the past, the time scale has been static for 10 years at a time, but we now anticipate more frequent updates. The time scale will be given a posting date and be available online, in both color and black-and-white versions.

GSA encourages the use of the time scale, boundary ages, and its terminology in all publications; strict enforcement, however, is not planned. The time scale will be kept as current as possible. Constructive comments are encouraged and should be addressed to editing@geosociety.org.

\section{REFERENCES CITED}

Gradstein, F., Ogg, J., Smith, A., et al., 2004, A Geologic Time Scale 2004: Cambridge University Press, 589 p.

Palmer, A.R., 1983, The Decade of North American Geology 1983 Geologic Time Scale: Geology, v. 11, p. 503-504, doi: 10.1130/0091 -7613(1983)11<503:TDONAG>2.0.CO;2.

*jgeiss@unm.edu 